\title{
Activation of the mTOR signaling pathway in breast cancer MCF-7 cells by a peptide derived from Porphyra yezoensis
}

\author{
SU-JIN PARK ${ }^{1}$, JINA RYU ${ }^{1}$, IN-HYE KIM ${ }^{2}$, YOUN-HEE CHOI ${ }^{2}$ and TAEK-JEONG NAM ${ }^{1,2}$ \\ ${ }^{1}$ Department of Food and Science, Pukyong National University, Busan 608-737; \\ ${ }^{2}$ Institute of Fisheries Science, Pukyong National University, Busan 619-911, Republic of Korea
}

Received June 25, 2014; Accepted September 26, 2014

DOI: 10.3892/or.2014.3557

\begin{abstract}
Seaweeds have beneficial nutritional and medicinal properties. Several studies have examined the polysaccharides found in the extracts of Porphyra yezoensis (PPY), although the effects of particular proteins have not been reported, and peptides from the marine alga PPY function in antitumor cell signaling, although the precise mechanism is not well understood. Apoptosis plays an important role in cell death, which affects cell proliferation. Generally, regulation of apoptosis requires participation of the p53 and Bcl-2 family by the mammalian target of rapamycin (mTOR) pathway, which is activated in a variety of malignant cancers. Autophagy is another signaling pathway that leads to degradation of cellular components by lysosomal activity, and the relationship between autophagy and cancer has been of interest for several years. The present study investigated mTOR pathway activation in MCF-7 cells treated with $500 \mathrm{ng}$ PPY for $24 \mathrm{~h}$ by assessing LC3 as a monitor of autophagy. We observed that the p53/NF- $\mathrm{kB}$ and mTOR pathways were affected by PPY, which contributes to our understanding of the functional relationship between the Bcl-2 family and mTOR under apoptotic conditions in MCF-7 cells.
\end{abstract}

\section{Introduction}

Breast cancer is the most common malignancy and the second most common cause of cancer-related deaths in females in the Western world, with an estimated 192,370 new cases and 40,170 deaths in the US in 2009 (1). Although advances in chemotherapy have significantly reduced the risk of disease recurrence and death, the recurrence of breast cancer due to chemotherapy failure or acquired resistance remains a major challenge (2).

Correspondence to: Professor Taek-Jeong Nam, Department of Food and Science, Pukyong National University, Busan 608-737, Republic of Korea

E-mail: namtj@pknu.ac.kr

Key words: Porphyra yezoensis, peptide, apoptosis, mTOR, siRNA, autophagy
Mammalian target of rapamycin (mTOR) is a highly conserved 289-kDa Ser/Thr kinase found in yeast and all eukaryotes, consisting of two distinct signaling complexes known as mTORC1 and mTORC2. It belongs to the phosphoinositide 3-kinase (PI3K) family of protein kinases and regulates two important downstream substrates, p70S6 kinase (p70S6K) and eukaryotic initiation factor 4B binding protein 1 (4EBP1) (3). The mTOR pathway is a major regulator of autophagy activated downstream of PI3K-Akt, a pathway commonly dysregulated in human cancer (4) and activated by HER2, insulin-like growth factor receptor, and estrogen receptor in breast cancer (5-8), suggesting that it may play an important role in the development of cancer and many other diseases (9).

Apoptosis plays an important role in regulating cell death by controlling cell proliferation through $\mathrm{p} 53$ and $\mathrm{Bcl}-2$ proteins. The Bcl-2 family is an important regulator of apoptosis $(10,11)$ that includes anti-apoptotic and pro-apoptotic members, such as Bcl-2, Bcl-xL, Mcl-1 and Bax $(12,13)$. The activation of Bcl-2 can be regulated by post-translational phosphorylation of Akt, mTOR, and p70S6K $(14,15)$. Akt regulates cell survival via various molecular mechanisms that include phosphorylation and the inactivation of pro-apoptotic proteins, such as Bad, glycogen synthase kinase-3 (GSK-3), forkhead, and caspase-9 $(16,17)$. As a downstream effector of $\mathrm{PI} 3 \mathrm{~K} / \mathrm{mTOR}$, Akt is constitutively activated in many types of human tumors, including breast cancer. Moreover, NF- $\mathrm{KB}$ and p53 signaling pathways are crucial modulators of cell survival and apoptosis $(18,19)$, as well as important regulators of Bcl-2 family genes (20-23).

Autophagy begins with the formation of double-membrane vesicles, known as autophagosomes, which engulf cytoplasmic constituents. The autophagosomes then fuse with lysosomes, allowing the sequestered contents to undergo degradation and recycling. Monoallelic loss of the essential autophagy gene, Beclin-1, has been found in $40-75 \%$ of human breast, prostate, and ovarian cancers, suggesting that autophagy may play a role in preventing these tumors (24). The production of inositol 1,4,5-triphosphate (PtIns3P) by Beclin-1 is essential for the recruitment of other autophagy-related gene (Atg) products critical for autophagosome formation. During the initiation phase, formation of the Atg5-Atg12 complex promotes the recruitment and conversion of cytosolic-associated protein light chain 3 (LC3-I) to LC3-II, the membrane-bound and lipidated form (25). 
This study investigated mTOR pathway activation in MCF-7 cells treated with PPY by assessing LC3 to monitor autophagy. We observed that the $\mathrm{p} 53 / \mathrm{NF}-\kappa \mathrm{B}$ and mTOR pathways were affected by PPY, which contributes to our understanding of the functional relationship between the Bcl-2 family and mTOR under apoptotic conditions in MCF-7 cells.

\section{Materials and methods}

Peptide preparation. The PPY method was performed as previously described (26). Briefly, the peptide PPY, found in Porphyra yezoensis, was synthesized by PEPTRON (Daejeon, Korea). Purification of PPY was performed using a Shimadzu Prominence HPLC apparatus, controlled using the software package Class-VP, 6.14 (Kyoto, Japan), on a C18 column (Shiesido Capcell Pak) in $0.1 \%$ triflouroacetic (TFA)/water and a gradient of $10-70 \%$ acetonitrile in $0.1 \%$ TFA with a flow rate of $1 \mathrm{~nm} / \mathrm{min}$ and $\mathrm{UV}$ detection at $220 \mathrm{~nm}$.

Cell culture. Human breast cancer MCF-7 cells were obtained from the Korean Cell Line Bank (Seoul, Korea). Cells were maintained in RPMI-1640 supplemented with $10 \%$ fetal bovine serum, $100 \mu \mathrm{g} / \mathrm{ml}$ penicillin and $100 \mathrm{ng} / \mathrm{ml}$ streptomycin at $37^{\circ} \mathrm{C}$ in a humidified atmosphere with $5 \% \mathrm{CO}_{2}$.

Western blot analysis. Proteins $(50 \mu \mathrm{g} / \mathrm{ml})$ were separated by $7.5-15 \%$ sodium dodecyl sulfate-polyacrylamide gel electrophoresis (SDS-PAGE) and transferred to a polyvinylidene fluoride (PVDF) membrane (Millipore, Billerica, MA, USA). The membrane was blocked with $1 \%$ bovine serum albumin (BSA) in TBS-T (10 mM Tris- $\mathrm{HCl}, 150 \mathrm{mM} \mathrm{NaCl}$, $\mathrm{pH} 7.5,0.1 \%$ Tween-20) and then incubated overnight with the indicated primary antibodies (diluted 1:1,000) in TBS-T containing $1 \%$ BSA with gentle shaking at $4^{\circ} \mathrm{C}$. The secondary antibody was a peroxidase-conjugated goat anti-mouse or rabbit antibody (diluted 1:10,000). Signals were detected using an enhanced chemiluminescence (ECL) western blotting kit (Amersham, Piscataway, NJ, USA).

siRNA transfection in vitro. The control and mTOR siRNA sequences were designed by cosmo GENETECH (Seoul, Korea). mTOR was targeted using the following siRNAs: sense, 5'-UGAACCCUGCCUUUGUCAUGC-3' and antisense, 5'-GCAUGACAAAGGCAGGGUUCA-3'. Briefly, MCF-7 cells were transfected with the control, non-targeting or mTORtargeted siRNAs using Lipofectamine (Invitrogen, Carlsbad, CA, USA) according to the manufacturer's instructions. The cells were cultured in the presence of the transfection mixture for $72 \mathrm{~h}$, and on the following day, the transfection mixture was replaced with fresh RPMI medium. After transfection, complete medium was added to a final volume of $1 \mathrm{ml}$, yielding a $50 \mathrm{nM}$ final concentration of siRNA in each well. After a 24-h incubation at $37^{\circ} \mathrm{C}$ and $5 \% \mathrm{CO}_{2}$, the transfected cells were refreshed with $1 \mathrm{ml}$ complete media and returned to the incubator.

\section{Results}

Expression of the mTOR pathway in MCF-7 cells. PI3K/Akt signaling is crucial in a variety of divergent physiological processes, including transcription, differentiation, apoptosis,

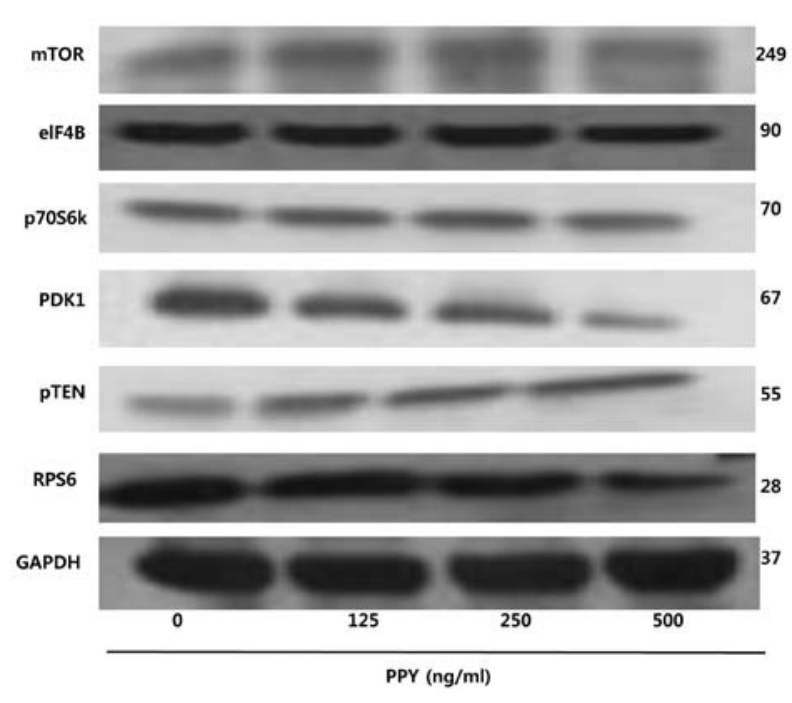

Figure 1. Effect of PPY on mTOR pathway expression. Cells were treated with increasing concentrations of PPY $(0-500 \mathrm{ng} / \mathrm{ml})$ for $24 \mathrm{~h}$, and the protein expression levels of mTOR, elF4B, p70S6K, PDK1, pTEN and RPS6 were analyzed by western blotting.

and metabolism (27). mTOR is a downstream kinase in the $\mathrm{PI} 3 \mathrm{~K} / \mathrm{Akt}$ pathway whose activation is correlated with an increase in PI3K/Akt-dependent Ser2448 phosphorylation (28) and regulates cell growth by integrating nutrient- and growth factor-derived signals $(29,30)$. Therefore, we examined activation of the mTOR pathway in MCF-7 cells (Fig. 1). There was a dose-dependent decrease in mTOR and p70S6K in the MCF-7 cells treated with PPY, which also decreased the level of phosphoinositide-dependent kinase 1 (PDK1). We previously demonstrated in MCF-7 cells that PPY increased the level of phosphatase and tensin homolog (PTEN) in a dosedependent manner, which was accompanied by decreased ribosomal protein S6 (RPS6). These results demonstrate that PPY inhibits MCF-7 cell growth.

p70S6K plays an important role in metastasis. $\mathrm{p} 70 \mathrm{~S} 6 \mathrm{~K}$ has been associated with poor prognosis and metastasis in breast cancer, but the underlying mechanisms are not well understood. To determine the downstream targets and mechanisms that may play a role in metastasis, western blot analysis was used to detect proteins that may be critical in cell attachment, motility, invasion and metastasis (31). In a dose-dependent manner, PPY decreased activation of p70S6K in MCF-7 cells and downregulated transglutaminase 2 (TG2), $\beta$-catenin, and focal adhesion kinase phosphorylation (p-FAK) (Fig. 2). TG2 is a multifunctional enzyme known for its calcium-dependent post-translational covalent cross-linking of proteins $(32,33)$, and TG2 expression on the cell membrane, as a result of its association with specific integrins, has been reported to promote cell survival signaling (34). These results demonstrated that p70S6K was involved in the metastasis of MCF-7 cells. In addition, p70S6K plays an important role in metastasis by regulating key proteins such as cyclin D1, PDCD4 and FAK, whereas E-cadherin, $\beta$-catenin and TG2 are essential for cell attachment, survival, and invasion, as well as metastasis in breast cancer (Fig. 3).

Activation of NF- $\kappa B$ and Bcl-2 family members. As shown in Fig. 4, the activities of NF- $\mathrm{\kappa B}$ and Bcl-2 were decreased, 


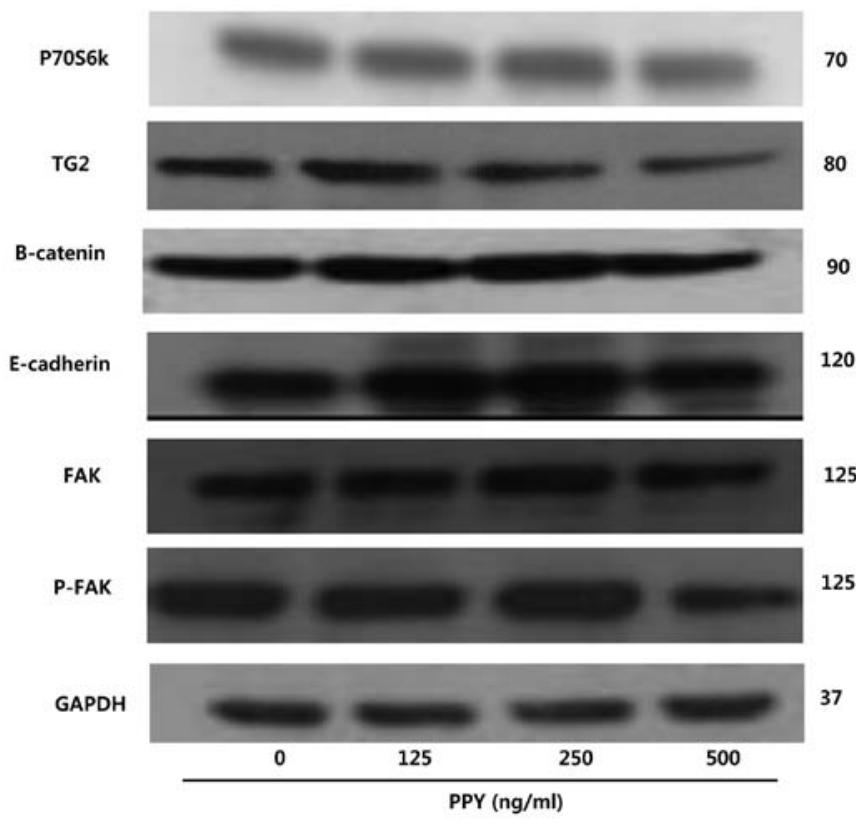

Figure 2. PPY inhibits cell migration and metastasis by targeting p70S6K Cells were treated with increasing concentrations of PPY $(0-500 \mathrm{ng} / \mathrm{ml})$ for $24 \mathrm{~h}$, and the protein expression levels of p70S6K, TG2, $\beta$-catenin, E-cadherin, FAK and p-FAK were analyzed by western blotting.

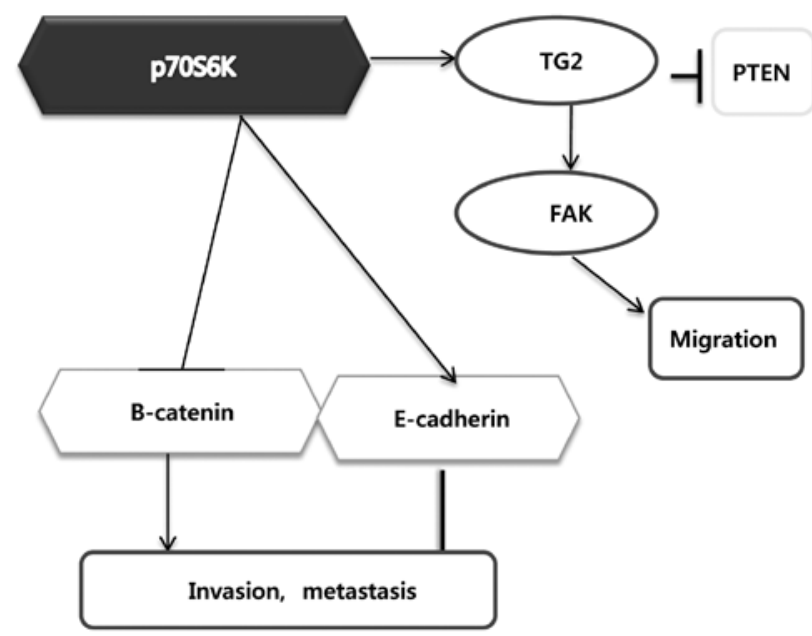

Figure 3. p70S6K plays an important role in metastasis by regulating key proteins essential for cell attachment, survival, invasion and metastasis in MCF-7 cells. The expression levels of FAK, $\beta$-catenin, c-cadherin and TG2 were analyzed by western blotting.

while those of $\mathrm{p} 53$, Bad, and Bax were increased by PPY. This indicated that PPY controls apoptosis regulator gene expression by downregulation of $\mathrm{p} 53$ and upregulation of NF- $\mathrm{kB}$ to stimulate PPY-induced apoptosis in MCF-7 cells. Importantly, this study also showed that the p53/NF- $\mathrm{BB}$ and PI3K/Akt/ mTOR pathways were affected by PPY, clarifying the functional relationship among NF- $\kappa \mathrm{B}, \mathrm{Bcl}-2$ family genes and mTOR following PPY treatment. This demonstrated that PPY might modulate anticancer and Akt/mTOR signaling. NF- $\mathrm{kB}$, which plays a pivotal role in cell survival, regulates a vast number of genes related to apoptosis, such as Bcl-2, Bax and Fas (35). Bcl-2 family members such as Bax and Bad promote
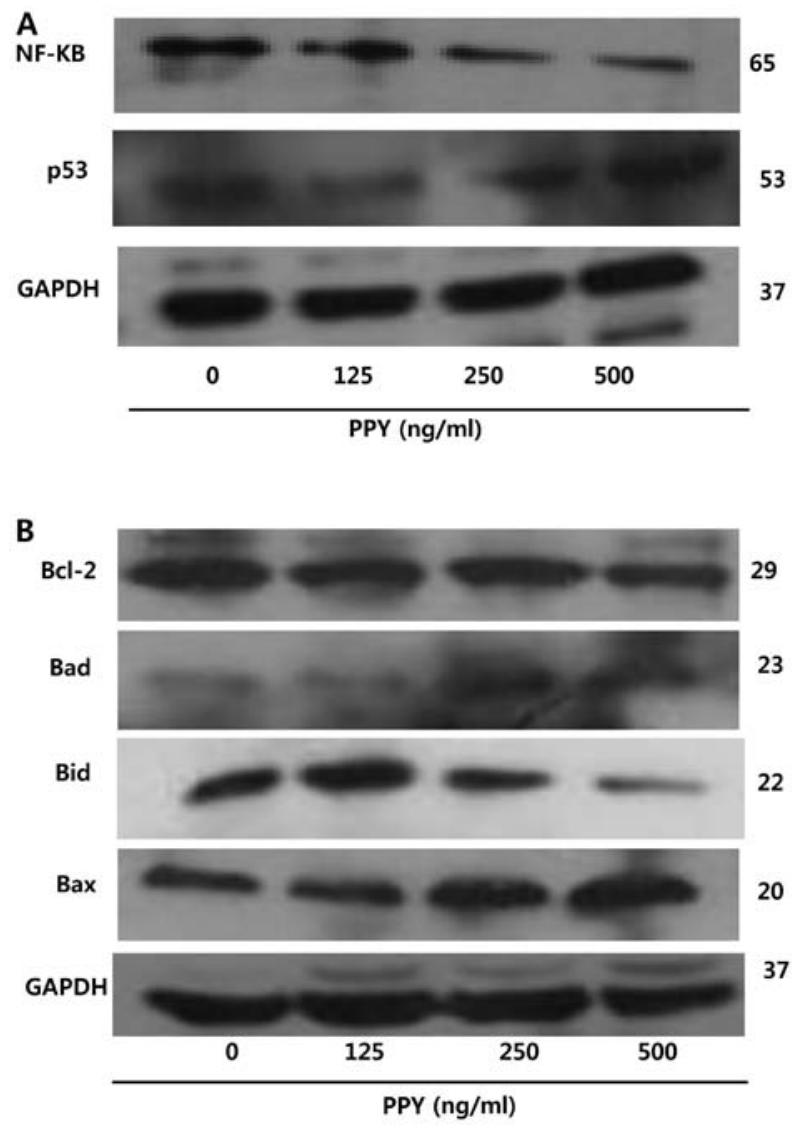

Figure 4. Effect of PPY on the expression of (A) NF- $\kappa$ B, p53 and (B) Bcl-2 family members. Cells were treated with increasing concentrations of PPY $(0-500 \mathrm{ng} / \mathrm{ml})$ for $24 \mathrm{~h}$, and the protein expression levels of NF- $\mathrm{kB}$, p53, $\mathrm{Bcl}-2, \mathrm{Bad}, \mathrm{Bid}$ and Bax proteins were analyzed by western blotting.

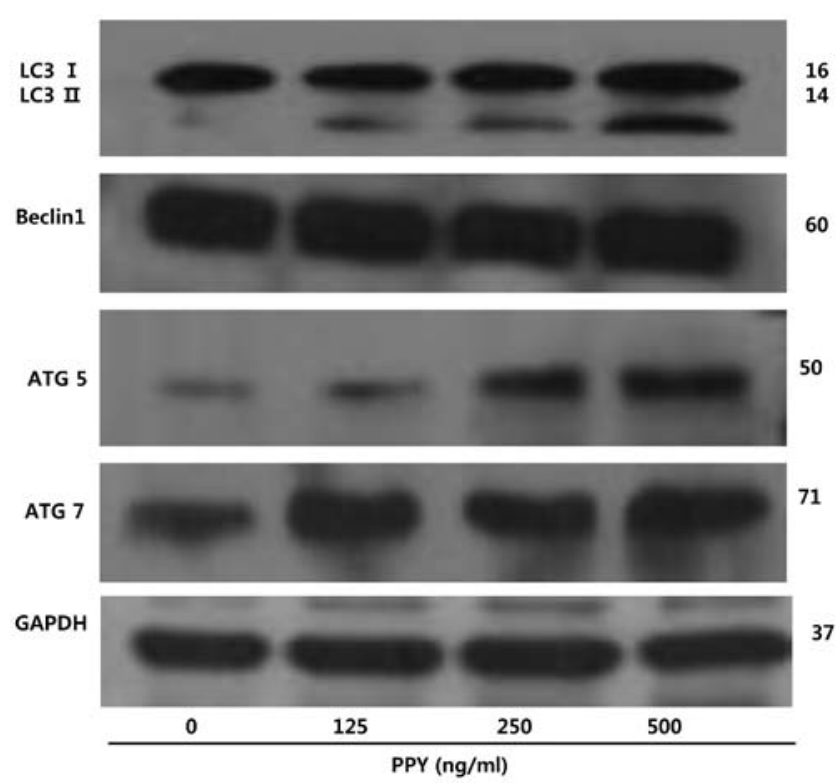

Figure 5. Effect of PPY on the expression of autophagy-related proteins. Cells were treated with increasing concentrations of PPY $(0-500 \mathrm{ng} / \mathrm{ml})$ for $24 \mathrm{~h}$, and the protein expression levels of LS3, Beclin-1, ATG5 and ATG7 proteins were analyzed by western blotting.

apoptosis, whereas other members such as Bcl-2 and Bcl-xL exert anti-apoptotic effects (36). 


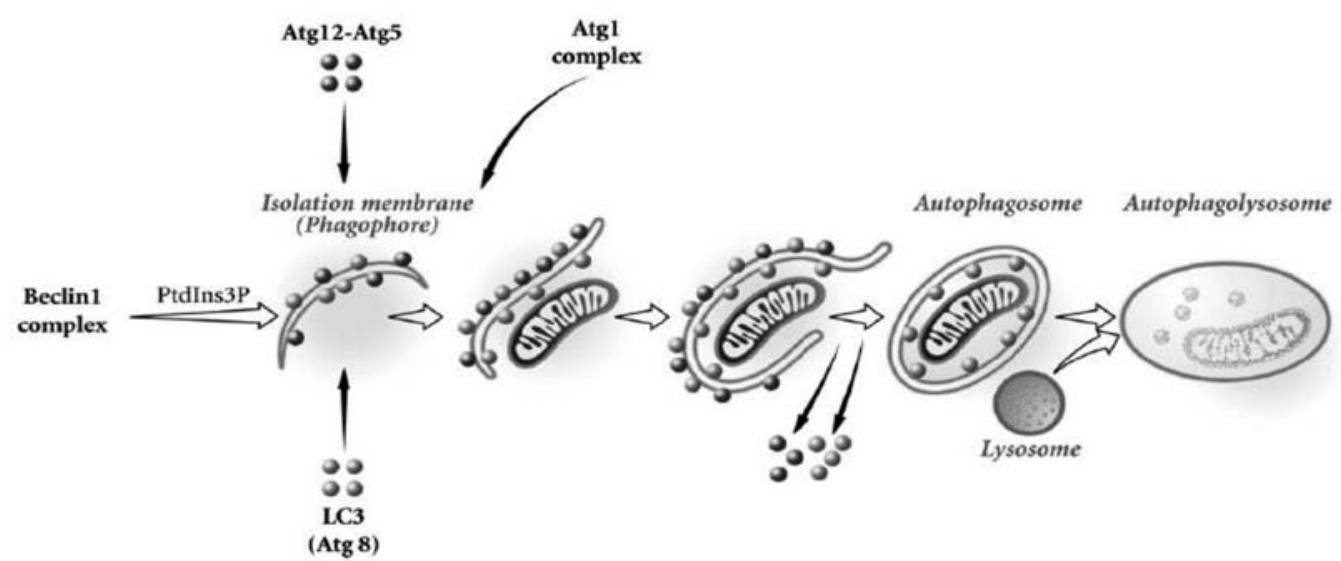

Figure 6. Proposed model for the role of autophagy. The process of autophagy is regulated by autophagy-related genes (Atg) and their homologs in various eukaryotic cells. The diagram shows the primary stages of autophagosome development, including phagophore formation, elongation, autophagosome formation and its fusion with the lysosome (Pattingre et al, 2008) (4).

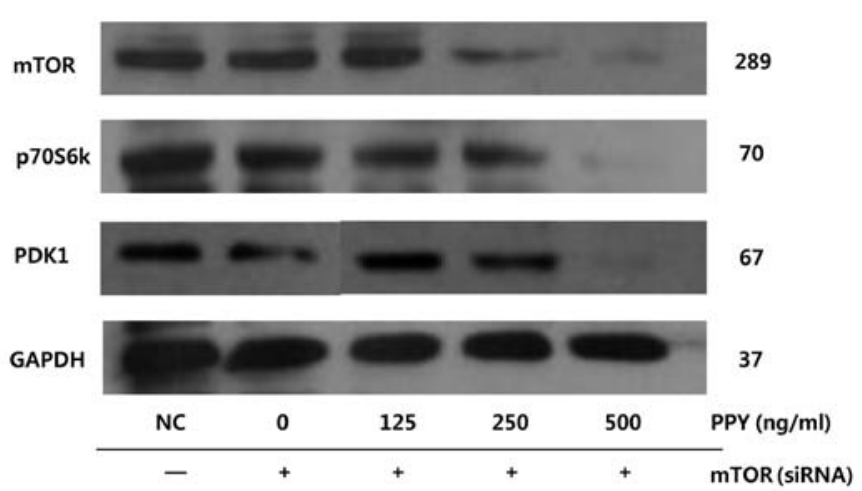

Figure 7. Effect of PPY following mTOR siRNA-mediated knockdown. Western blot analysis of mTOR signaling pathway proteins after mTOR siRNA transfection.

The role of autophagy. Autophagy is important in a variety of other cellular processes, including the recycling of aged or damaged organelles, remodeling of cellular structures during development, cell death, and protection against bacterial infection (37). As shown in Fig. 5, we detected increased expression of autophagy-associated proteins such as LC3, Beclin-1, Atg5 and Atg7. When MCF-7 cells were treated with $500 \mathrm{ng} / \mathrm{ml}$ PPY for $24 \mathrm{~h}$, an increase in LC3 protein expression was observed compared with the untreated cells. As a specific marker for autophagy, LC3 has been widely used to monitor autophagy. Lipidation of microtubule-associated protein LC3-1, an autophagy marker, coats autophagosomes during autophagy and is converted to LC3-II resulting in delayed electrophoretic mobility (38). Beclin-1 is an essential autophagic gene that contributes to initial vesicle nucleation and formation of the autophagosome, whereas Atg5 participates in autophagic vesicle elongation and completion (39). Fig. 6 summarizes what we know about the anatomy of autophagy and the role of Atg and other proteins involved in the formation and maturation of autophagosomes (40). These results support the idea that PPY induces autophagy, inhibits tumor growth and induces apoptosis in MCF-7 cells. In addition, we demonstrated that PPY-induced autophagy occurred via the Akt/mTOR pathway.
mTOR knockdown by PPY in MCF-7 cells. To further elucidate the role of PPY in autophagy, we used small interfering RNA (siRNA) conjugated with PPY to knock down mTOR expression in MCF-7 cells. MCF-7 cells were transfected with siRNA/Lipofectamine complexes using different PPY concentrations $(0,125,250,500 \mathrm{ng} / \mathrm{ml})$. Total protein was harvested 3 days after siRNA treatment and western blot analysis was used to assess mTOR expression. There was a significant reduction in mTOR expression by siRNA when the PPY concentration was $500 \mathrm{ng} / \mathrm{ml}$ (Fig. 7). In addition, p70S6K and PDK protein levels were significantly suppressed by mTOR siRNA treatment in vitro compared with transfection of non-targeting siRNA controls.

\section{Discussion}

Cancer is caused by alterations in gene expression and is one of the major causes of mortality worldwide (29), since all cancers acquire resistance to long-term anticancer drug treatments. In the MCF-7 cells used in this study, we found that a peptide isolated from Porphyra yezoensis can target the mTOR signaling pathway, which has emerged as a critical regulator of cell proliferation, growth and translation (29). Recent studies have shown that aberrant activation of mTOR is involved in many cancers, including ovarian carcinoma, lung cancer, prostate cancer and mantle cell lymphoma (30). This study showed that PPY markedly decreased mTOR and p70S6K, and high concentrations of PPY decreased PDK1. Upon activation, mTOR and its downstream target $\mathrm{p} 70 \mathrm{~S} 6 \mathrm{~K}$ promoted cell growth by inducing protein synthesis (41). These results suggest that activation of mTOR plays an important role in the pathogenesis of MCF-7 cells.

The process of metastasis has three major steps. The first is the separation of cells from their original tissue; the second is immune surveillance in the circulation; and the third is the homing of cells to other tissues (31). In this study, we focused on metastasis since we wanted to determine the link between p70S6K and cell attachment proteins, such as TG2 and FAK, which were previously reported to be involved in metastasis (31). PPY decreased activation of p70S6K in MCF-7 cells and downregulated TG2, $\beta$-catenin and p-FAK proteins 


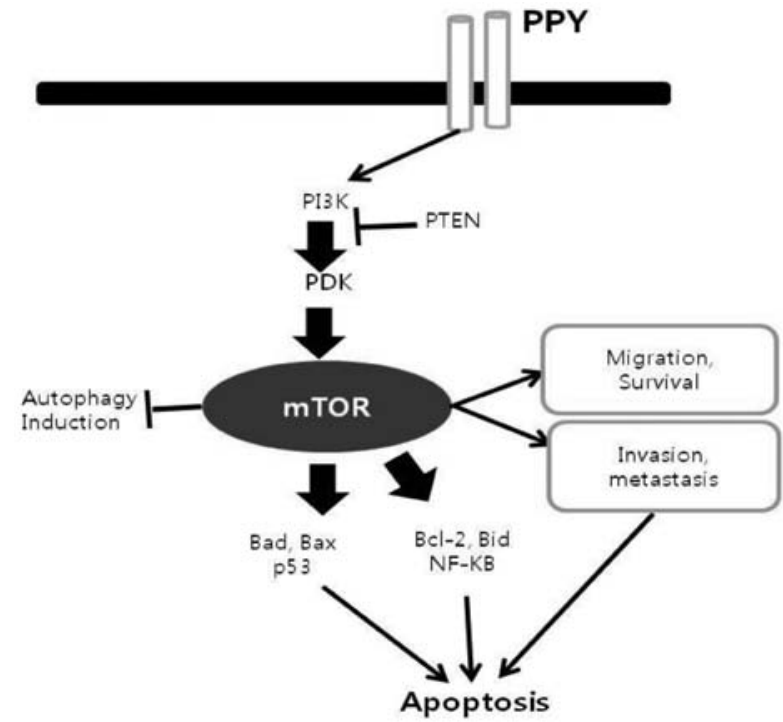

Figure 8 . Proposed model for autophagy and metastasis mediated by mTOR signaling.

(Fig. 2). Downregulation of p70S6K also inhibited TG2 and $\beta$-catenin expression. These results demonstrated that $\mathrm{p} 70 \mathrm{~S} 6 \mathrm{~K}$ is involved in the metastasis of MCF-7 cells.

Expression of the apoptosis regulating factors, p53 and Bcl-2/Bax, correlates with apoptosis of cancer cells, including breast cancer (42). In the present study, we examined the involvement of $\mathrm{p} 53$ and $\mathrm{Bcl}-2$ family members in PPY-induced apoptosis of MCF-7 cells. We found that the expression of $\mathrm{NF}-\kappa \mathrm{B}$ and Bcl-2 were decreased in the PPY-treated MCF-7 cells (Fig. 4). p53 modulates Bcl-2 during apoptosis in two ways: by direct trans-repression of Bcl-2 transcription and by transcription-independent, direct binding to Bcl-2 (40). p53 released from the p53-Bcl-2 complex can directly induce mitochondrial permeabilization and subsequent apoptosis (43). Importantly, these results are the first to show that PPY can regulate apoptosis regulator gene expression by downregulating $\mathrm{NF}-\kappa \mathrm{B}$ and upregulating p53 activity in MCF-7 cells. Additionally, PPY enhanced the mTOR/p70S6K signaling pathway in MCF-7 cells.

Autophagy is a catabolic process in which cells respond to various stress stimuli, such as hypoxia, nutrients, nutrient starvation and DNA damage (37). During this process, proteins or organelles, sequestered by double-membrane structures, fuse with lysosomes and are subsequently degraded by lysosomal hydrolases to be recycled and sustain metabolism (44). As shown in Fig. 5, we observed increased expression of autophagy-associated proteins LC3, Beclin-1, Atg5 and Atg7, revealing that PPY induced autophagy accompanied by apoptosis in MCF-7 cells. Collectively, these results indicate that autophagy provides a protective mechanism against PPY-induced apoptosis.

mTOR plays a critical role in cell cycle regulation, and rapamycin, a known inhibitor of mTOR (45), can inactivate mTOR specifically. Because mTOR regulates cell proliferation, it has been investigated extensively as a potent target for both anticancer and anti-restenotic therapies (46). Rapamycin and its analogues are reported to effectively prevent cardiac and pulmonary fibrosis in vivo $(47,48)$, and mTOR promotes cell growth and proliferation by regulating protein synthesis. It is therefore conceivable that mTOR knockdown may also control or alter cell proliferation $(49,50)$. Transfection of mTOR siRNA in MCF-7 cells downregulated mTOR expression, as monitored by western blotting. Knockdown of mTOR occurred only when the PPY concentration was $500 \mathrm{ng} / \mathrm{ml}$. Compared with the non-targeting siRNA complexes, mTOR siRNA complexes reduced mTOR protein levels in MCF-7 cells (Fig. 7), confirming the suppression of targeted gene expression via RNA interference.

In conclusion, this study investigated the effect of PPY on the inhibition of MCF-7 cell proliferation, as well as the possible mechanism of growth inhibition. This study demonstrated the apoptosis of PPY cells and we identified regulation of the mTOR signaling pathway and autophagy in MCF-7 cells (Fig. 8).

\section{Acknowledgements}

This research was supported by the Basic Science Research Program through the National Research Foundation of Korea (NRF) funded by the Ministry of Education (2012R1A6A1028677).

\section{References}

1. American Cancer Society, Cancer Facts and Figures. American Cancer Society, Atlanta, GA, 2009.

2. He X, Wang Y, Zhu J, Orloff M and Eng C: Resveratrol enhances the anti-tumor activity of the mTOR inhibitor rapamycin in multiple breast cancer cell lines mainly by suppressing rapamycininduced AKT signaling. Cancer Lett 301: 168-176, 2011.

3. Hay N and Sonenberg N: Upstream and downstream of mTOR. Genes Dev 18: 1926-1945, 2004.

4. Pattingre S, Espert L, Biard-Piechaczyk M and Codogno P: Regulation of macroautophagy by mTOR and Beclin 1 complexes. Biochimie 90: 313-323, 2008 .

5. Bärlund M, Forozan F, Kononen J, et al: Detecting activation of ribosomal protein S6 kinase by complementary DNA and tissue microarray analysis. J Natl Cancer Inst 92: 1252-1259, 2000.

6. Sekulic A,Hudson CC,Homme JL, et al: A direct linkage between the phosphosphoinositide 3-kinase-AKT signaling pathway and the mammalian target of rapamycin in mitogen-stimulated and transformed cells. Cancer Res 60: 3504-3513, 2000.

7. Lmoki K, Li Y, Zhu T, Wu J and Guan KL: TSC2 is phosphorylated and inhibited by AKT and suppresses mTOR signaling. Nat Cell Biol 4: 648-657, 2002.

8. Chung J, Kuo CJ, Crabtree GR and Bieris J: Rapamycin FKBP specifically blocks growth-dependent activation of and signaling by the 70 kd S6 protein kinases. Cell 69: 1227-1236, 1992.

9. Holland EC, Sonenberg N, Pandolfi PP and Thomas G: Signaling control of mRNA translation in cancer pathogenesis. Oncogene 23: 3138-3144, 2004.

10. Adams JM and Cory S: The Bcl-2 protein family: arbiters of cell survival. Science 281: 1322-1326, 1998

11. Antonsson B and Martinou JC: The Bcl-2 protein family. Exp Cell Res 256: 50-57, 2000.

12. Yin XM, Oltvai $\mathrm{ZN}$ and Korsmeyer SJ: $\mathrm{BH} 1$ and $\mathrm{BH} 2$ domain of $\mathrm{Bcl}-2$ are required for inhibition of apoptosis and heterodimerization with Bax. Nature 369: 321-323, 1994.

13. Reed JC: Bcl-2 family protein: regulators of apoptosis and chemoresistance in hematologic malignancies. Semin Hematol 34: 9-19, 1997.

14. Johnstone RW, Ruefli AA and Lowe SW: Apoptosis: a link between cancer genetics and chemotherapy. Cell 108: 153-164, 2002.

15. Malaguarnera L: Implications of apoptosis regulators in tumorigenesis. Cancer Metastasis Rev 23: 367-387, 2004.

16. Khwaja A: Akt is more than just a Bad kinase. Nature 401: 33-34, 1999.

17. McCormick F: Cancer: survival pathways meet their end. Nature 428: 267-269, 2004. 
18. Karin M, Cao Y, Greten FR and Li ZW: NF-kappaB in cancer: from innocent bystander to major culprit. Nat Rev Cancer 2: 301-310, 2002.

19. Steele RJ and Lane DP: p53 in cancer: a paradigm for modern management of cancer. Surgeon 3: 197-205, 2005.

20. Haldar S, Negrini M, Monne M, Sabbioni S and Croce CM: Downregulation of Bcl-2 by p53 in breast cancer cells. Cancer Res 54: 2095-2097, 1994.

21. Miyashita T and Reed JC: Tumor suppressor p53 is a direct transcriptional activator of the human bax gene. Cell 80: 293-299, 1995.

22. Bentires-Alj M, Dejardin E, Viatour P, Van Lint C, Froesch B, Reed JC, Mervile MP and Bours V: Inhibition of the NF-kappa B transcription factor increases Bax expression in cancer cell lines. Oncogene 20: 2805-2813, 2001.

23. Heckman CA, Mehew JW and Boxer LM: NF-kappaB activates $\mathrm{Bcl}-2$ expression in $\mathrm{t}(14 ; 18)$ lymphoma cells. Oncogene 21 : 3898-3908, 2002.

24. Qu X, Yu J, Bhagat G, Furuya N, Hibshoosh h and Troxel A: Promotion of tumorigenesis by heterozygous disruption of the beclin1 autophagy gene. J Clin Invest 112: 1809-1820, 2003.

25. Matshushita M, Suzuki NN, Obara K, Fujioka Y, Ohsumi Y and Inagaki F: Structure of Atg5.Atg16, a complex essential for autophagy. J Biol Chem 282: 6763-6772, 2007.

26. Park SJ, Ryu J, Kim IH, Choi YH and Nam TJ: Induction of apoptosis by a peptide from Porphyra yezoensis: regulation of the insulin-like growth factor I receptor signaling pathway in MCF-7 cells. Int J Oncol 45: 1011-1016, 2014.

27. Yuan TL and Cantley LC: PI3K pathway alterations in cancer: variations on theme. Oncogene 27: 5497-5510, 2008

28. Xu X, Sakon M, Nagano H, Hiraoka N, et al: Akt2 expression correlates with prognosis of human hepatocellular carcinoma. Oncol Rep 11: 25-32, 2004.

29. Faivre S, Kroener G and Raymond E: Current development of mTOR inhibitors as anticancer agents. Nat Rev Drug Discov 5: 671-688, 2006.

30. Dann SG and Thomas G: The amino acid sensitive TOR pathway from yeast to mammals. FEBS Lett 580: 2821-2829, 2006.

31. Akar U, Ozpolat B, Mehta K, et al: Targeting p70S6k prevented lung metastasis in a breast cancer xenograft model. Mol Cancer Ther 9: 1180-1187, 2010.

32. Fesus L and Szondy Z: Transglutaminase 2 in the balance of cell death and survival. FEBS Lett 579: 3297-3302, 2005.

33. Herman JF, Mangala LS and Mehta K: Implications of increased tissue transglutaminase (TG2) expression in drug-resistant breast cancer (MCF-7) cells. Oncogene 25: 3049-3058, 2006.

34. Fesus L and Piacentini M: Transglutaminase 2: an enigmatic enezyme with diverse function. Trends Biochem Sci 27: 534-539, 2002.
35. Malek R, Borrowicz KK, Jargiełło M and Czuczwar SJ: Role of nuclear factor kappaB in the in the central nervous system. Pharmacological Rep 59: 25-33, 2007.

36. Jurgensmeier JM, Xie Z, Deveraux Q, Ellerby L, Bredesen D and Reed JC: Bax directly induced release of cy tochrome c from isolated mitochondria. Proc Natl Acad Sci USA 95: 4997-5002, 1998.

37. Levine B and Kroemer G: Autophagy in the pathogenesis of disease. Cell 132: 27-42, 2008.

38. Folkman J: Role of angiogenesis in tumor growth and metastasis. Semin Oncol 29: 15-18, 2002.

39. Zhang DM, Liu JS, Deng LJ, et al: Arenobufagin, a natural bufadienolide from toad venom, induces apoptosis and autophagy in human hepatocellular carcinoma cells through inhibition of PI3K/Akt/mTOR pathway. Carcinogenesis 34: 1331-1342, 2013.

40. Eskelinen FL: Maturation of autophagic vacuoles in Mammalian cells. Autophagy 1: 1-10, 2005.

41. Jing Ji and Zheng PS: Activation of mTOR signaling pathway contributes to survival of cervical cancer cells. Gynecol Oncol 117: 103-108, 2010.

42. Cho MY, Park SY, Park S, Lee YR, Han GD and Kim JA: Geranyl derivative of phloroacetophenone induces cancer cell-specific apoptosis through Bax-mediated mitochondrial pathway in MCF-7 human breast cancer cells. Biol Pharm Bull 35: 98-104, 2012.

43. Lee KB, Byun HJ, Park SH, Park CY, Lee SH and Rho SB: CYR61 controls 553 and NF- $\mathrm{KB}$ expression through PI3K/AKT/ mTOR pathways in carboplatin-induced ovarian cancer cells. Cancer Lett 315: 86-95, 2012.

44. Klionsky DJ: The molecular machinery of autophagy: unanswered questions. J Cell Sci 118: 7-18, 2005.

45. Dumont FJ and Su Q: Mechanism of action of the immunosuppressant rapamycin. Life Sci 58: 373-395, 1996.

46. Windecker S, Roffi M and Meier B: Sirolimus eluting stent: a new era in interventional cardiology? Curr Pharm Des 9: 1077-1094, 2003.

47. Gao XM, Wong G, Wang B, et al: Inhibition of mTOR reduces chronic pressure overload cardiac hypertrophy and fibrosis. J Hypertens 24: 1663-1670, 2006.

48. Simler NR, Howell DC, Marshall RP, et al: The rapamycin analogue SDZ RAD attenuates bleomycin-induced pulmonary fibrosis in rat. Eur Respir J 19: 1124-1127, 2002.

49. Achenbach TV, Barrow RK and Heerneier K: Oligonucleotide-based knockdown technologies: antisense versus RNA interference. Chembiochem 4: 928-935, 2003.

50. Burnet PE, Barrow RK, Cohen NA, Snyder SH and Sabatini DM: RAFT1 phosphorylation of the translational regulators p70 S6 kinase and 4E-BP1. Proc Nat Acad Sci USA 95: 1432-1437, 1998. 